\section{Replacing religion}

\section{Charles H. Bennett}

The Hour of Our Delight: Cosmic Evolution, Order, and Complexity. By Hubert Reeves. Freeman: 1991. Pp.256. $\$ 17.95, £ 14.95$.

A GLANCE at the index (Nazis, Neutrinos ... Open Universe, Oppenheimer, Optimism, Order, Organization) hints at the scope of this book, the English version of L'heure de s'enivrer: L'univers a-t-il un sens? (Editions du Seuil, 1986). The superficial impression is of a cobbling together of two familiar but incompatible genres: a stinging indictment of civilization's destructiveness is followed by a careful elementary exposition of thermodynamics and cosmology. But the actual aim of the book is to fashion, out of the world view offered by modern science, a replacement for the sense of purpose formerly provided by religion and traditional myth.

By the early twentieth century, science had thoroughly undermined this sense of purpose by discovering the vastness of space, our random origin through chemical and biological evolution, and our apparent aloneness, but most seriously by predicting the eventual obliteration of all our accomplishments in a monotonous final state of thermal equilibrium. That gloomy prediction, Reeves points out, was based on the misconception of a static Universe: in the expanding Universe we now know we inhabit, entropy is diluted faster than it is produced, and we have, in principle, the possibility of an infinite event-filled future. Our thermodynamic death sentence commuted, things begin to look not so bad.

Indeed, Reeves makes them look rather traditional. 'Complexity', which the Universe produces in abundance as a side effect of its supercooling, takes over the job of good; our propensity and growing capability to destroy it take over from evil; and our fifteen-thousandmillion-year gestation period and chemical kinship with all other matter and life give us a sense of place. Our divine mission? To assist the Universe in giving birth to further complexity, which we can do only if we outgrow our present tendency to self-extinction. How do we do this? Not by any hasty, zealous programme of action, but as a gentle side effect of contemplative delight in the Universe as we now understand it.

Except for the commutation of the thermodynamic death sentence, these ideas are not at all new; accordingly, Reeves' purpose in putting them in a book was not to propose them, but rather to propagate them, especially to readers with no scientific background.

The book begins with the 'death urge', or tendency toward self-destruction, of our own or other technologically advanced civilizations, which may account for our not having heard any radio messages from them. This section is marred by a self-castigating anthropocentrism (for our senselessly cruel wars, environmental abuse and the unstoppable development of nuclear weapons) and romanticization of nature (where male seals fight, but do not kill one another) which in my opinion only distracts the reader from understanding the interplay of creative and destructive processes, both human and non-human, in the Universe as a whole. A less passionate discussion of, say, the genetics or economics of cooperation versus competition, or of the biosphere's response to major insults such as nuclear war or the events leading to mass extinctions in the past, would have been more helpful.

The next section, on the Universe's 'life urge', or complexity-generating tendency, is much better. While not attempting to define complexity itself, Reeves gives a thorough account of its creation in environments of gravitational, nuclear or chemical disequilibrium, as well as describing the supercooling which leads to these disequilibria. He codifies

\section{Chop and change}

\section{K. S. Bawa}

The Conservation Atlas of Tropica Forests: Asia and the Pacific. Edited by N. M. Collins, J. A. Sayer and T. C. Whitmore. Macmillan: 1991. Pp.256. £65. Published in the United States by Simon and Schuster; $\$ 95$.

DESPITE worldwide concern, the rate of tropical deforestation is accelerating and in 1989 was almost twice that in 1979. (Norman Myers, Deforestation Rates in Tropical Forests and their Climatic Implications, Friends of the Earth, London). The pace of change is alarming, and only a small fraction of the original forests enjoy a conservation status. According to Collins, Sayer and Whitmore, the protected areas in seven Asian countries (Bangladesh, China (including Taiwan), India, Burma, Papua New Guinea, the Philippines and Vietnam) constitute less than 2.2 per cent of the moist tropical forest originally present. In two other countries, Indonesia and Malaysia, protected forests account for less than ten per cent of the original area under moist tropical forests. We know from species-area relationships that a 90 per cent reduction of the area roughly translates into the loss of 50 per cent of key ideas in memorable symbols such as William Tell's arrow, which stands for a special initial condition inferred from its consequences

With the help of this metaphor he treats the anthropic principle - the doctrine that physical laws or initial conditions of the Universe must be such as to have allowed the development of intelligent beings. Like most scientists, he regards it as a heuristic principle, rather than as a direct basis for inference, where it might serve as an unholy ally of the death urge, forcing us into existence against all odds, then abandoning us to our own devices.

Perhaps because I can no longer put myself in the place of a layperson, I found Reeves' explanations at times too simplified and didactic. I enjoyed the comparison of nuclear, atomic and molecular energy-level diagrams in the appendix, and wished he had found other ways to surprise and delight me with concrete examples of the manifold unexpected variety of the Universe while he was telling me about it. Unfortunately, this kind of pedagogic spectacle is much harder to produce in cosmological than in biological natural-history writing.

Charles H. Bennett is at the IBM Research Division, T. J. Watson Research Center, Yorktown Heights, New York 10598. USA.

the species. Thus, unless the protected areas can be increased and better secured, and degradation of the remaining areas prevented, thousands, perhaps millions, of species are doomed to extinction within a relatively short period.

Assault on forest ecosystems, as the editors of this book point out, stems from several sources: expanding human populations coupled with a shrinking natural resource base, misguided government policies, inappropriate models of economic growth, inadequate valuation of forest resources and logging without proper controls. Although several factors contribute to the current losses in biodiversity, there is little agreement about the extent of losses, relative importance of each factor and possible solutions to the problem. This volume represents an admirable effort on the part of the World Conservation Minority Centre and the International Union of Conservation of Nature to present "objective and carefully researched information" to foster a constructive debate on conservation and management of forest resources. Collins et al. provide an overview of the extent of tropical forests in Asia and the Pacific, threats to these forests and prospects for their conservation.

The book is divided into two parts. The first part covers the general issues such as forest wildlife, shifting cultiva- 